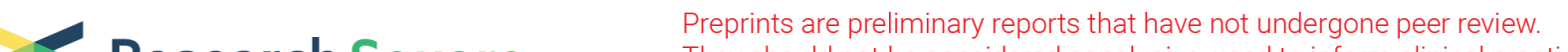 Research Square
or referenced by the media as validated information.
}

\section{Mathematical Modelling of a Novel Hetero-junction Dual SIS ZnO-Si-SnO Solar Cell}

Kaustuv Dasgupta ( $\square$ kaustuv.dasgupta@msit.edu.in )

Meghnad Saha Institute of Technology https://orcid.org/0000-0003-1819-4627

Utpal Gangopadhyay

Meghnad Saha Institute of Technology

Anup Mondal

Indian Institute of Engineering Science and Technology

Soma Ray

Meghnad Saha Institute of Technology

\section{Original Research}

Keywords: SIS solar cell, ZnO, SnO, MATLAB, hetero junction, Silicon

Posted Date: January 27th, 2021

DOI: https://doi.org/10.21203/rs.3.rs-157052/v1

License: (9) (i) This work is licensed under a Creative Commons Attribution 4.0 International License. Read Full License

Version of Record: A version of this preprint was published at Silicon on April 19th, 2021. See the published version at https://doi.org/10.1007/s12633-021-01090-8. 


\title{
Mathematical Modelling of a Novel Hetero-junction Dual SIS ZnO-Si-SnO Solar Cell
}

\author{
Kaustuv Dasgupta*a, ${ }^{*}$ Anup Mondal ${ }^{\mathrm{c}}$, Soma Ray ${ }^{\mathrm{a}, \mathrm{b}}$, Utpal Gangopadhyay ${ }^{\mathrm{a}}$ \\ ${ }^{a}$ Centre for Advance Research in Renewable Energy and Sensor Technology,Meghnad Saha institute of Technology, Kolkata-700150, India \\ ${ }^{b}$ Centre for Green Energy and Sensor System, IIEST, Howrah-711103, India \\ ${ }^{c}$ Department ofChemistry, IIEST, Howrah-711103, India
}

*Correspondence to kaustuvdasgupta83@gmail.com

\begin{abstract}
For the last few decades scientists across the world have achieved significant improvement in performance of conventional silicon p-n junction solar cell. Sophisticated high temperature doping technology is unavoidable in the fabrication of these conventional solar cells. Back in 1970s scientists proposed an alternative solar cell technology with Schottky barrier which can cut down the burden on thermal budget of manufacturing process. Later the metalsemiconductor Schottky barrier further modified with hetero junction semiconductor-semiconductor solar cells. A thin intrinsic layer sandwiched between semiconductor-semiconductor junctions can repair the junction defect efficiently. These SIS solar cells became popular for its low thermal budget and considerable efficiency. In this paper we have tried to propose a mathematical model of a novel dual side SIS solar cell which is basically a multi junction solar cell. We have introduced a third semiconductor layer ( $\mathrm{SnO})$ at the back side of the cell which can provide an inversion layer much similar to PERT solar cell. This structure is first of its kind and thus a theoretical analysis is required before implementation. We have studied the effect of this back field on the performance of the cell and propose a mathematical model based on reciprocity theorem of charge collection. The efficiency of conventional $\mathrm{ZnO}-\mathrm{pSi}$ SIS solar cell was computed $\sim 5.2 \%$ while the back $\mathrm{SnO} \mathrm{p}^{+}$layer is expected to enhance the efficiency up to $\sim 7.9 \%$ according to our mathematical model. We have concluded with significant mathematical justification to implement this structure with proposed electro-chemical experiments.
\end{abstract}

Keywords: SIS solar cell; ZnO; SnO; MATLAB; hetero junction; Silicon

\section{Introduction}

In 1883 Fritts reported a non-conventional solar cell with very poor efficiency $(\sim 1 \%)$ replacing the silicon homojunction with metal-semiconductor Schottky junction [1]. In later years scientists have significantly improved the efficiency of Schottky barrier solar cell by optimizing the metal layer thickness and introducing an insulator layer in between the metal-semiconductor to minimize the junction interface crystal defect [2][3]. The basic principle of operation of these MIS solar cells later inspired scientists to adopt the similar technology in semiconductor-insulator -semiconductor hetero-junction solar cells (SIS). The choice of different semiconductor combinations and different layer deposition techniques like enhanced the efficiency of the solar cell in following years. Metal oxide semiconductors like $\mathrm{SnO}_{2}$ [4], $\mathrm{TiO}_{\mathrm{X}}[5]$, ITO[6], $\mathrm{ZnO}$ [7] became popular in investigating the performance of SIS solar cell. Modern layer deposition techniques like sputtering, CVD, ALD immensely helped this technology to grow. The latest development of SIS solar cell using ITO-SiO $2-\mathrm{n}-\mathrm{Si}$ was reported as $16.6 \%$ efficiency by Untila et al in 2020 [8]. Still the major trailing factor for SIS solar cell in race of solar cell technology is its poor efficiency but this SIS technology seems to be the winner for its extremely low thermal budget in comparison with conventional crystalline Si solar cell. Different metal oxide semiconductors layer can be grown over Si even by room temperature CBD or Sol-gel process [9]. On the other hand the recent advancement of Si solar cell is designed with PERT technology where rear surface is totally passivated by back surface field. Highly efficient PERT Si solar cell $(\sim 24.5 \%)$ has been reported by Zhao et al [10]. Inspiration of our design of novel dual SIS solar cell is to adopt the PERT technology in SIS solar cell by introducing a rear surface passivated field. This filed was designed by another SIS junction at the back. The semiconductor materials for these two SIS junctions (front surface and back surface) were chosen considering their carrier concentration and electron affinity. The semiconductor properties of the metal oxides used in our proposed cell structure were sourced from existing experimental data published elsewhere.

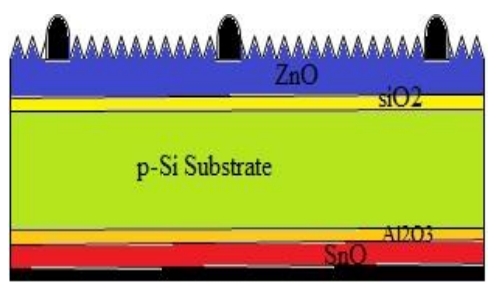

Fig. 1 Dual SIS structure

The proposed dual SIS collar cell structure is depicted in Fig. 1. We have considered p type mono crystalline diamond cut $\mathrm{Si}$ as the substrate. The Front surface SIS is designed with $\mathrm{ZnO}$ (Semiconductor)- $\mathrm{SiO}_{2}$ (Insulator)-p- 
Si(semiconductor) where the back surface field is designed with another SIS field consisting with p$\mathrm{Si}$ (Semiconductor)- $\mathrm{Al}_{2} \mathrm{O}_{3}$ (Insulator)- $\mathrm{SnO}$ (Semiconductor). Al the layers can be grown over the $\mathrm{p}-\mathrm{Si}$ substrate by suitable CBD or Sol-gel or low temperature thermal process [11][12][13][14]. The thermal budget reduction is a major advantage of our proposed structure. We have theoretically estimated the performance of the proposed solar cell. The collection probability of the minority carrier was formulated for different section of the proposed cell by solving the Poisson's equation and applying reciprocity theorem condition. Further the layer thickness was varied and estimated the effect on voltage-current profile.

\section{Band Diagram and carrier flow}

The energy band diagram and the corresponding band bending of the proposed solar cell structure is shown in Fig.2.

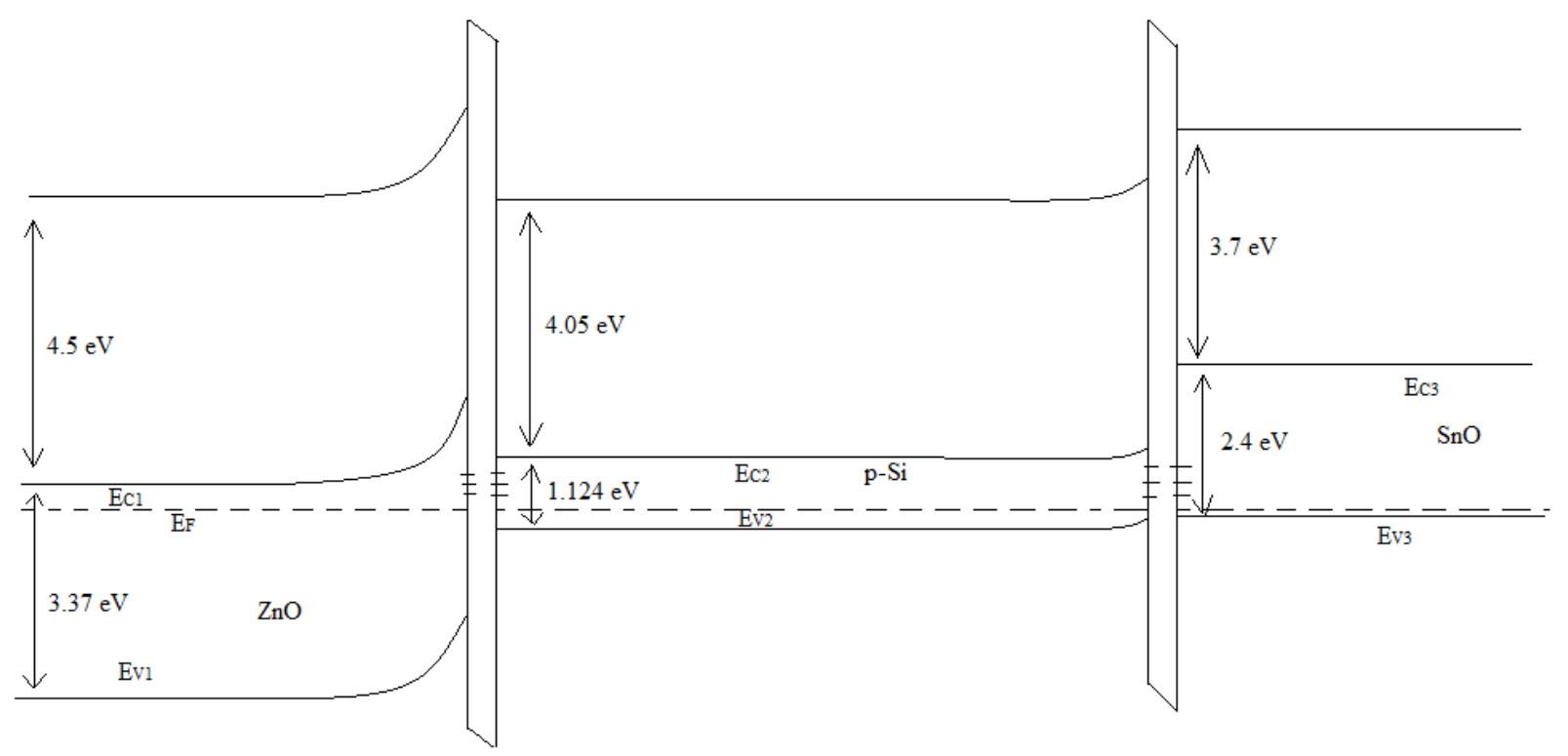

Fig. 2 Energy band diagram of dual SIS structure

Here the we have are referring prefix 1,2 and 3 for associated parameters of $\mathrm{ZnO}, \mathrm{p}$-Si and $\mathrm{SnO}$ respectively. Different material properties required for the mathematical modelling of this dual SIS solar cell are considered from different experimental works reported elsewhere. The parameters that we have considered are listed below in Table 1.

Table 1 Material properties considered in the mathematical modelling (at 300K)

\begin{tabular}{|c|c|c|c|}
\hline Parameter & $\mathrm{ZnO}(\mathrm{n}$-type $)$ & $\mathrm{Si}(\mathrm{p}$-type) & $\mathrm{SnO}\left(\mathrm{p}^{+}\right.$-type) \\
\hline Energy band gap $(\mathrm{eV})$ & $\mathrm{E}_{\mathrm{g} 1}=3.37[15]$ & $\mathrm{E}_{\mathrm{g} 2}=1.124[16]$ & $\mathrm{E}_{\mathrm{g} 3}=2.4[17]$ \\
\hline Electron affinity $(\mathrm{eV})$ & $\chi_{1}=4.5[15]$ & $\chi_{2}=4.05[16]$ & $\chi_{3}=3.7[18]$ \\
\hline Effective mass of electron $\left(\mathrm{m}_{0}\right)$ & $m_{n 1}^{*}=0.24[19]$ & $m_{n 2}^{*}=1.08$ & $m_{n 3}^{*}=0.4[20]$ \\
\hline Effective mass of hole $\left(\mathrm{m}_{0}\right)$ & $m_{p 1}^{*}=0.59[19]$ & $m_{p 2}^{*}=0.81$ & $m_{p 3}^{*}=0.9[20]$ \\
\hline Electron mobility $\left(\mathrm{cm}^{2} / \mathrm{V}-\mathrm{s}\right)$ & $\mu_{\mathrm{n} 1}=200[19]$ & $\mu_{\mathrm{n} 2}=1400$ & $\mu_{\mathrm{n} 3}=3[21]$ \\
\hline Hole mobility $\left(\mathrm{cm}^{2} / \mathrm{V}-\mathrm{s}\right)$ & $\mu_{\mathrm{p} 1}=50[19]$ & $\mu_{\mathrm{p} 2}=470$ & $\mu_{\mathrm{p} 2}=7[17]$ \\
\hline Electron lifetime $(\mathrm{s})$ & & $\tau_{\mathrm{n} 2}=29 \times 10^{-6}[22]$ & $\tau_{\mathrm{n} 3}=4 \times 10^{-9}[21]$ \\
\hline Hole lifetime $(\mathrm{s})$ & $\tau_{\mathrm{p} 1}=2.8 \times 10^{-9}[23]$ & $\tau_{\mathrm{p} 2}=10 \times 10^{-6}[22]$ & \\
\hline Electron concentration $\left(\mathrm{cm}^{-3}\right)$ & $\mathrm{N}_{\mathrm{d} 1}=4.8 \times 10^{18}[24]$ & $\mathrm{N}_{\mathrm{d} 2}=6.7 \times 10^{4}$ & $\mathrm{~N}_{\mathrm{a} 3}=5 \times 10^{18}[25]$ \\
\hline Hole Concentration $\left(\mathrm{cm}^{-3}\right)$ & & $\mathrm{N}_{\mathrm{a} 2}=10^{15}$ & \\
\hline
\end{tabular}

When the device reaches its equilibrium the Fermi level has to be constant throughout the device. The actual position of the Fermi level depends upon the majority carrier concentration. In case of metal oxide semiconductors the carrier concentration depends upon its deposition process and temperature. We have considered the different concentration for $\mathrm{ZnO}$ for different layer deposition techniques as reported. Then we have studied the effect of the deposition process on the performance of the solar cell which is discussed later in this paper. The band bending and junction notch approximation is done by solving the Maxwell's equations at the junction boundary. For the $\mathrm{ZnO}-$ 
Si(p-type) junction the built in potential can be estimated from the band diagram as shown in equation 1 .

$\Psi_{1}=\frac{1}{q}\left[\left(\chi_{2}+E_{C 2}-E_{F}\right)-\left(\chi_{1}+E_{C 1}-E_{F}\right)\right]$

Here $\mathrm{E}_{\mathrm{C}}$ is the conduction band energy and $\mathrm{E}_{\mathrm{F}}$ is the Fermi energy level of the device. Further applying the Fermidirac statistical distribution of electron we can get[26],

$$
\begin{aligned}
& E_{C 1}-E_{F}=k_{B} T \ln \left(\frac{N_{C 1}}{N_{d 1}}\right) \ldots \ldots . .(2) \\
& \left.E_{C 2}-E_{F}=E_{G 2}-\left(E_{F}-E_{V 2}\right)=E_{G 2}-k_{B} T \ln \left(\frac{N_{V 2}}{N_{a 2}}\right) \ldots \ldots \ldots \text { ( }\right)
\end{aligned}
$$

$E_{V}$ is the valance band energy. Substituting equation 2 and 3 in equation 1 we can get the expression for built in potential as,

$$
\Psi_{1}=\frac{1}{q}\left[\chi_{2}-\chi_{1}+E_{G 2}-k_{B} T \ln \left(\frac{N_{V 2} N_{C 1}}{N_{a 2} N_{d 1}}\right)\right] \ldots \ldots . . .(4)
$$

The notch height for this junction will be the difference in conduction band energy, i.e.

$$
\Delta E=E_{C 2}-E_{C 1}
$$

Then the band bending is drawn obeying the Matsuura equation.[27]

The second junction creates a back surface $\mathrm{p}-\mathrm{p}^{+}$field. The band bending will occur due to the change in concentration gradient of acceptors. Since $\mathrm{SnO}$ shows a good high density p type semiconductor $\left(\sim 10^{18} / \mathrm{cm}^{3}\right)[25]$ and the p-Si substrate is chosen with $10^{14} / \mathrm{cm}^{3}$ acceptor concentration. This results a considerable band bending and back surface field to enhance the collection probability of the solar cell. The band diagram in this case is drawn with the same approach as $\mathrm{ZnO}$ (n-type) and p-Si junction. The built in junction potential in this case can be written from equation 4 . We have considered $\mathrm{E}_{\mathrm{G} 2}$ to match the datum voltage level with $\psi_{1}$.

$$
\Psi_{2}=\frac{1}{q}\left[\chi_{3}-\chi_{2}+E_{G 3}-E_{G 2}-k_{B} T \ln \left(\frac{N_{V 3} N_{C 2}}{N_{a 3} N_{d 2}}\right)\right] \ldots \ldots . .(6)
$$

This field sweeps away the light generated carriers to reach the junction 1 and hence get collected. We have considered the insulation layer in each junction $10 \AA$, Which is thin enough to allow the carrier to pass due to tunnelling effect. The pinning of carriers as an effect of same energy state tunnelling is shown in the band diagram by small pinning lines.

The photon entering through the front surface $\mathrm{ZnO}$ layer creates photo generated carriers in different part of the solar cell. The location of absorption of photon depends up on the energy of the photon and attenuation constant of the material. Most of the photon gets attenuated before reaching the second junction hence a very few carrier will be collected by the second junction. But the rear junction field provide a drift to the generated carrier to reach to the junction before recombination. As shown in the energy band diagram the electron flow will be towards the negative slope and hence we can have a net photo generated current from left to right in the device.

\section{Dark saturation current}

In our design of dual SIS structure we have considered two junctions of different carrier concentration. This results two depletion region and two built in potential as equated in equation 4 and 6 . The photo generated current due one junction depends upon the voltage across other junction. The total photo generated current depends on the collection probability which is discussed in the next section. The built in potential for two different junctions are cumulative and thus the voltage drop across the equivalent diodes must be in series. The dark saturation current is controlled by this built in potential of the cell. The dark saturation current densities for two junctions can be calculated as a function of acceptor and donor carrier concentrations, diffusion coefficient and diffusion length [28].

$$
J_{0}=q e^{-q \phi / k T}\left[N_{a 2} \sqrt{\frac{D_{p 1}}{\tau_{p 1}}}+N_{d 1} \sqrt{\frac{D_{n 2}}{\tau_{n 2}}}\right] \ldots \ldots . .(7)
$$

In equation $7, \varphi$ is the built in potential, For a single SIS (ZnO-Si) cell $\varphi=\Psi_{1}$. Where as, for the proposed dual SIS ( $\mathrm{ZnO}-\mathrm{Si}-\mathrm{SnO})$ cell the built in potential $\varphi=\Psi_{1}+\Psi_{2}$.

The diffusion coefficient D was estimated from Einstein relationship $D=\frac{k T}{q} \mu \ldots \ldots . .(8)$

\section{Photo generated current}


The photo generated current basically involves with two mechanisms, one is the carrier generation due to absorption of photon, and other is the collection of the carrier drifted due to the effect of depletion region electric field. As we have discussed earlier in dual SIS cell we have two depletion region electric fields in fort and rear junction. So the collection of the photo current will be due to simultaneous effect of these two built in fields. All the generated carriers do not get collected by the junction. A factor called collection probability $\left(\mathrm{C}_{\mathrm{P}}\right)$ plays an important role to determine the ratio of generated to collected carrier. In 1985 Donolato published his path-breaking proposition to estimate the collection probability of photo generated minority carrier under photo illuminacence, which is well recognized as reciprocity theorem [29]. Later he reconstructed the theorem in 1994 for two dimensional application [30]. The theorem can be approximated in one dimensional and stated as "The current collected by p-n junction as a unit carrier point charge is generated at a point $\mathrm{P}(\mathrm{x})$ ( where $\mathrm{x}$ is the distance of point $\mathrm{P}$ from surface) is quantitively same as excess minority charge density at point $\mathrm{P}(\mathrm{x})$ due to unit density of carrier at the p-n junction edge". This novel observation was mathematically expressed by him in the transport equation,

$D \nabla^{2} C_{P}(x)-\frac{1}{\tau} C_{P}(x)=0 \ldots \ldots . .(9)$

We have incorporated this theorem to solve for the collection probability for our proposed solar cell. We are having three different material regions in this design.

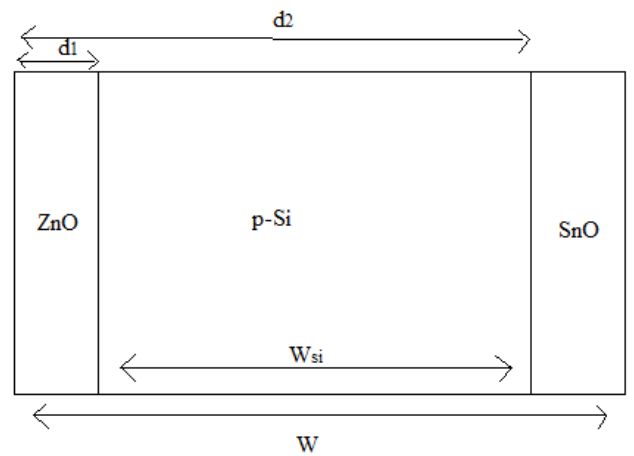

Fig. 3 Different semiconductor region in dual SIS structure

In Fig. 3 different semiconductor regions is shown with their dimension. We have applied the reciprocity theorem for these three regions. The general solution of equation 9 can be given as,

$C_{P}(x)=A e^{-x / L}+B e^{x / L}$

Where, $\mathrm{L}$ is the diffusion length.

$L=(D \tau)^{1 / 2}$

Different boundary conditions were taken for three different regions to find the constant A and B and then we solved the equation 9 to get the expression of $\mathrm{C}_{\mathrm{p}}(\mathrm{x})$.

Region I: ZnO layer

The two boundary conditions are taken as, $C_{P}\left(d_{1}\right)=1 \ldots \ldots . . .(11)$

At the edge of the depletion region, all the carriers are collected. The collection of charges at the front surface is characterized by the reduced surface recombination velocity $\mathrm{s}_{\mathrm{f}}=\mathrm{S}_{\mathrm{f}} / \mathrm{D}_{\mathrm{pl}}$. As explained by Donolato we got the second boundary condition.

$-\frac{\partial C_{P}(0)}{\partial n_{f}}=s_{f} C_{P}(0)$.

Solving this we get the expression for $\mathrm{C}_{\mathrm{P}}(\mathrm{x})$. The complete solution of equation 9 under these conditions can be 
found by reforming the solution as described by Hermele et al.[31]

$C_{P 1}(x)=\frac{\cosh \left[\left(W_{s i}-d_{1}+x\right) / L_{p 1}\right]+L_{p 1} s_{f} \sinh \left[\left(W_{s i}-d_{1}+x\right) / L_{p 1}\right]}{\cosh \left[W_{s i} / L_{p 1}\right]+L_{p 1} s_{f} \sinh \left[W_{s i} / L_{p 1}\right]}$ for $d_{1} \geq x \geq 0$

The surface recombination velocity $\left(\mathrm{S}_{\mathrm{f}}\right)$ for $\mathrm{ZnO}$ surface was taken as $10^{5} \mathrm{~cm} / \mathrm{s}$ [32].

Region II: p-Si layer

In the Si region if the photo carriers are generated at any of the junction edges that will be immediately collected.

This gave us two boundary conditions,

$C_{P}\left(d_{1}\right)=1$

and

$C_{P}\left(d_{2}\right)=1$

Solving transport equation with these conditions we got the solution for region II.

$C_{P 2}(x)=\left(\frac{e^{d_{1} / L_{2}}}{1+e^{-W_{s i} / L_{2}}}\right) e^{-x / L_{2}}+\left(\frac{e^{-d_{1} / L_{2}}}{1+e^{W_{s i} / L_{2}}}\right) e^{x / L_{2}}$ for $d_{2} \geq x \geq d_{1}$

We have assumed that all the carriers can tunnel through the insulator layer, sandwiched between the semiconductors.

Region III: SnO layer

The boundary conditions for the $\mathrm{p}^{+}$layer was taken from the similar argument of region I.

$C_{P}\left(d_{2}\right)=1 \ldots \ldots . .(17)$

and

$-\frac{\partial C_{P}(W)}{\partial n_{b}}=s_{b} C_{P}(W)$

We get the solution similar to region I.

$C_{P 3}(x)=\frac{\cosh \left[\left(W+d_{2}-x\right) / L_{n 3}\right]+L s_{b} \sinh \left[\left(W+d_{2}-x\right) / L_{n 3}\right]}{\cosh \left[W / L_{n 3}\right]+L s_{b} \sinh \left[W / L_{n 3}\right]}$ for $d_{2} \geq x \geq W$.

Here the surface recombination velocity is taken as $400 \mathrm{~cm} / \mathrm{s}$ [33]. The surface recombination velocity can be controlled by appropriate passivating layers.

The total photo generated current density thus can be calculated as,

$$
\begin{aligned}
J_{L}= & q\left[\int_{0}^{d_{1}} \int_{\lambda=280 \mathrm{~nm}}^{370 \mathrm{~nm}}\left((1-R(\lambda)) \alpha_{1}(\lambda) H_{0}(\lambda) e^{\left(-\alpha_{1} x\right)} d \lambda\right) C_{P 1}(x) d x\right] \\
& +q\left[\int_{d_{1}}^{d_{2}} \int_{\lambda=280 \mathrm{~nm}}^{370 n m}\left((1-R(\lambda)) \alpha_{2}(\lambda) H_{0} e^{\left(-\alpha_{1} d_{1}\right)} e^{\left(-\alpha_{2} x\right)} d \lambda\right) C_{P 2}(x) d x\right] \\
& +q\left[\int_{d_{1}}^{d_{2}} \int_{\lambda=370 n m}^{1100 n m}\left((1-R(\lambda)) \alpha_{2}(\lambda) H_{0} e^{\left(-\alpha_{2} x\right)} d \lambda\right) C_{P 2}(x) d x\right] \\
& +q\left[\int_{d_{2}}^{w} \int_{\lambda=280 n m}^{370 n m}\left((1-R(\lambda)) \alpha_{3}(\lambda) H_{0} e^{\left(-\alpha_{1} d_{1}\right)} e^{\left(-\alpha_{2} d_{2}\right)} e^{\left(-\alpha_{3} x\right)} d \lambda\right) C_{P 3}(x) d x\right] \\
& +q\left[\int_{d_{2}}^{w} \int_{\lambda=370 n m}^{460 n m}\left((1-R(\lambda)) \alpha_{3}(\lambda) e^{\left(-\alpha_{2} W_{S i}\right)} e^{\left(-\alpha_{3} x\right)} d \lambda\right) C_{P 3}(x) d x\right] \ldots \ldots . .(20)
\end{aligned}
$$

The bandgap of $\mathrm{ZnO}$ is $3.37 \mathrm{eV}$. The photons having lesser energy than bandgap energy will not get absorbed by the $\mathrm{ZnO}$ layer. As a result for the majority of the wavelengths of the light ( $>370 \mathrm{~nm}$ ) $\mathrm{ZnO}$ layer will act like transparent 
window layer. Similarly wavelengths greater than $460 \mathrm{~nm}$ will not get absorbed by SnO layer.

Here $\alpha$ is the absorption coefficient of the media. Absorption coefficient of $\mathrm{ZnO}$ layer was formulated from the experimental result provided by Park et al. [34]

$\alpha_{1}(\lambda)=6.64 \times 10^{5} \times \sqrt{\left(\frac{h c}{\lambda}-E_{g 1}\right)}$

Absorption coefficient of Si layer for the spectra was considered as the data provided Green et al [35]. The absorption coefficient for $\mathrm{SnO}$ layer was considered from the experimental result reported by Liu et al. [36]

$\alpha_{3}(\lambda)=4.2 \times 10^{5} \times \sqrt{\left(\frac{h c}{\lambda}-E_{g 3}\right)} \ldots \ldots \ldots \ldots \ldots$

The photon flux data was fed to equation 24 from AM 1.5 irradiance standard data. $R(\lambda)$ was taken from the micro textured surface reflectance data [37].

\section{Series and shunt resistance}

The series resistance arises from emitter resistance, base resistance and contact resistance.

$R_{s}=R_{b}+R_{e}+R_{c}$

In proposed dual SIS structure the base is $\mathrm{SnO}$ layer white the emitter is $\mathrm{ZnO}$ layer. The base and emitter resistance was calculated from the following equations.

$$
\begin{aligned}
& R_{b}=\frac{W-d_{1}}{A \sigma_{3}} \ldots \\
& R_{e}=\frac{d_{1}}{q \mu_{n 1} N_{d 1}} .
\end{aligned}
$$

The contact resistance as calculated as a function of $\mathrm{ZnO}$ layer carrier concentration from graph obtained by Schroder et al [38].

$$
R_{c}=10^{\left(-5 \times \log _{10}\left(N_{d 1}\right)+96.6\right)} \times 0.1 \times 10^{4}
$$

Here all the resistances were calculated per unit area and the contacts were assumed to cover $10 \%$ of total area. As the ideality factors were considered to be unity the shunt resistance also considered to be very high as $1.5 \mathrm{k}$ ohm.

\section{Result and discussion}

The conventional V-I equation of the solar cell can be derived from its equivalent circuit.

$$
I=a J_{L}-a J_{0} \exp \left[\frac{q\left(V+a J_{L} R_{S}\right)}{n k T}\right]-\frac{V+a J_{L} R_{S}}{R_{S H}} \ldots \ldots . .(27)
$$

$\mathrm{a}$ is the surface area of the cell. Here we are considering the edge recombination to be negligible and the operating voltage is large enough to consider the ideality factor $n=1$.[39]

All the parameters that are mentioned in equation 27 was computed with MATLAB. We have plotted different parameters for different sections of the device and for different wavelengths. The result helped us to analyze the performance and improvement of the proposed dual SIS ( $\mathrm{ZnO}-\mathrm{p}$ Si-SnO) cell with respect to single $\mathrm{SIS}(\mathrm{ZnO}-\mathrm{p} \mathrm{Si})$ cell. The simulated results showed a significant improvement on open circuit voltage and short circuit current. This resulted a higher efficient dual SIS solar cell than single SIS structure.

Improvement of short circuit current depends on the light generated current. The back surface field enhance the collection probability as discussed earlier. 


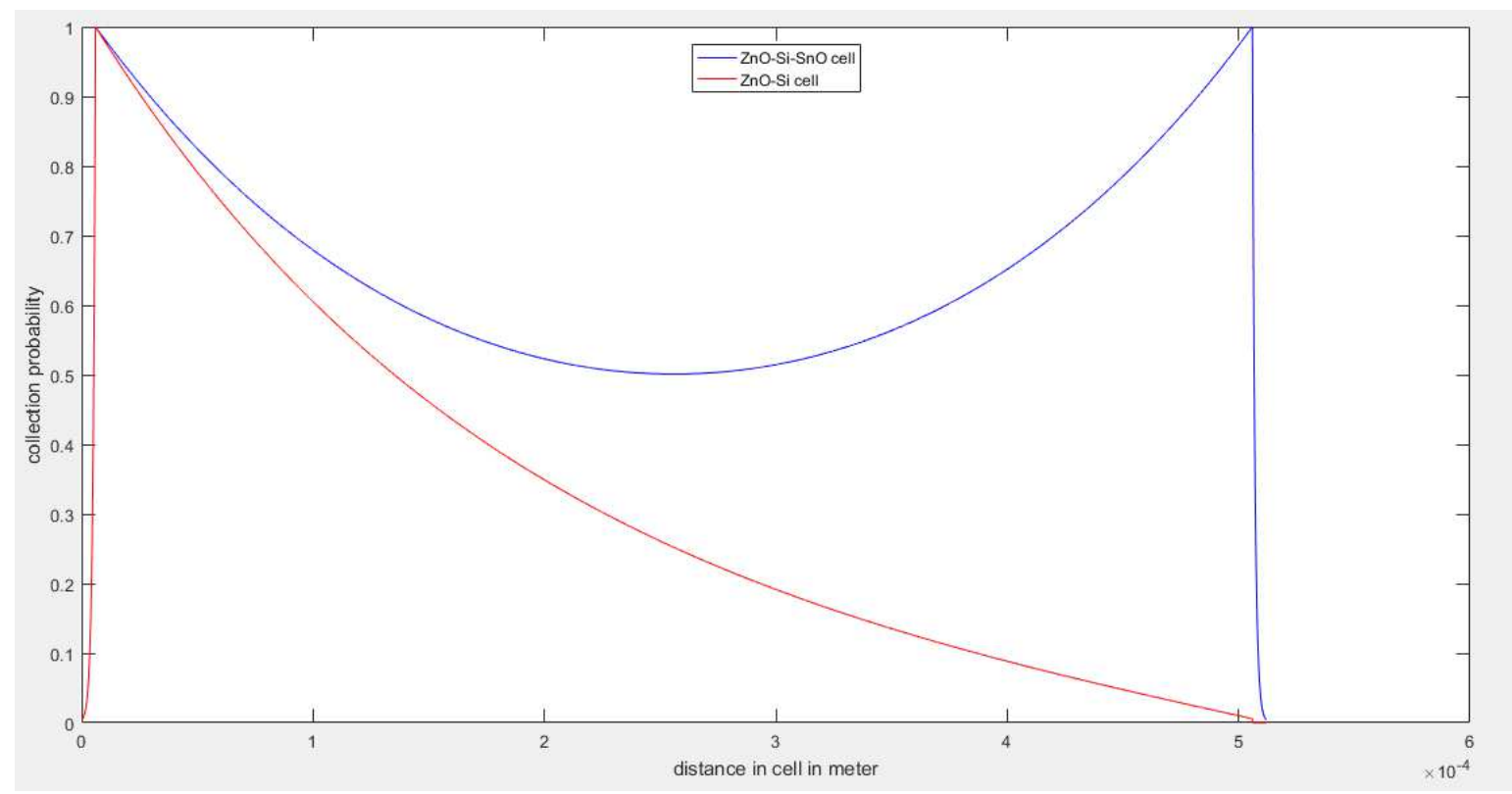

Fig. 4 Collection probability

Fig 4 shows the collection probability of photo generated carriers inside the device. We have considered the thickness of both $\mathrm{ZnO}$ and $\mathrm{SnO}$ film $150 \mathrm{~nm}$ and the p-Si substrate of thickness 500 micron. The improvement of collection probability in dual SIS cell seems much overwhelming over the single SIS cell as shown in Fig 4. The major enhancement of collection probability can be observed as the light penetrates deeper inside the cell. Here we must acknowledge the fact that as photon beams are penetrated more inside the cell it gets attenuated. The attenuation depends upon $\alpha$ which is a function of the wavelength. The attenuation constant $\alpha$ is very high for lesser wavelengths. Thus almost all the photon flux gets attenuated as infra red wave penetrates through the cell. Almost no photon flux remains where the effective collection probability is improved for the back surface field. So the region where collection probability is largely enhanced there is no more generated carrier to get collected. For the higher wavelengths of the spectra the attenuation is less. This implies that photon flux can get inside deeper in the cell without losing much of its strength. The advantage of higher collection probability near the back surface field is more effective for ultra violet range of the spectra.

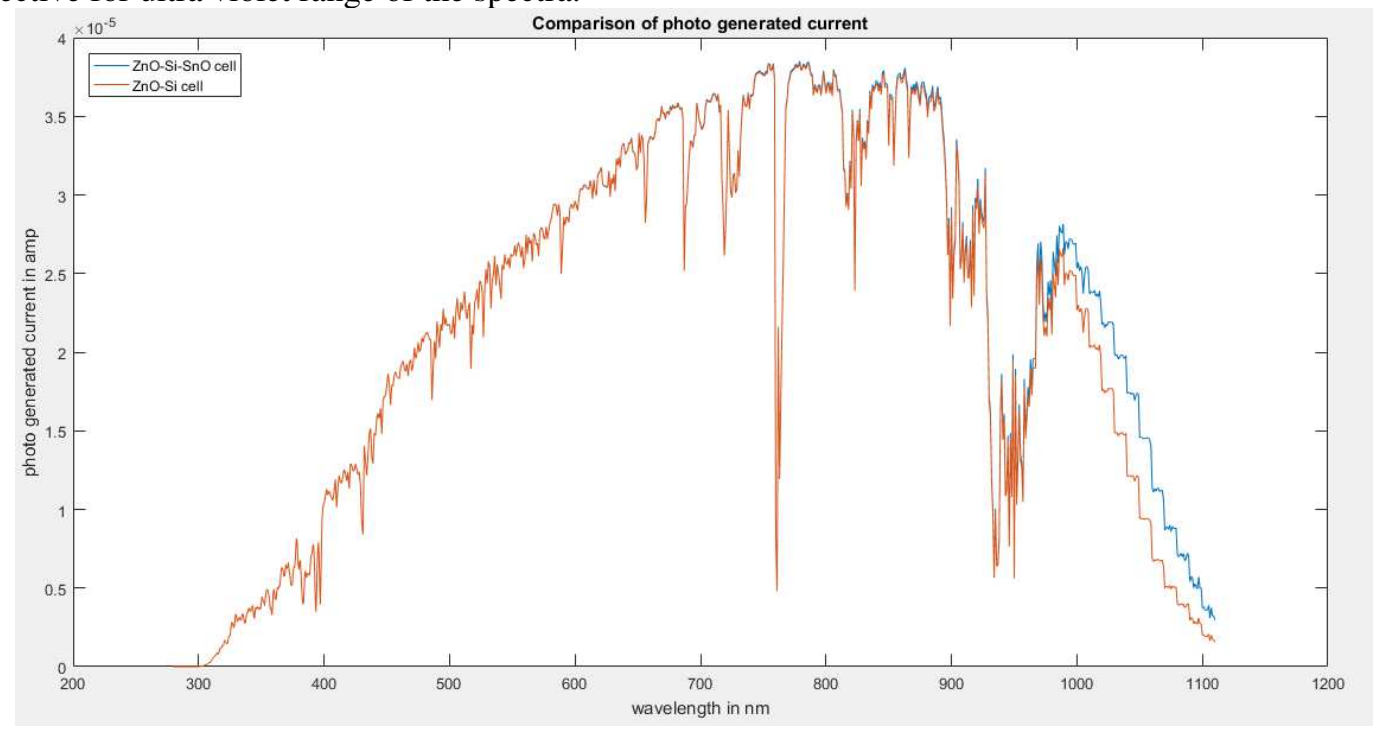

Fig. 5 Photo generated current for different wavelength

In Fig 5 we can see the simulated output of Photo generated current for different wavelength of the spectra. This 
result is justifying our analysis. We can observe the improvement of photo-generated current is prominent only for higher wavelength photons. A significant improvement can be observed beyond the visual range of the spectra. A total increment of $2.8224 \%$ of photo-generated current has been computed in dual SIS structure with respect to single SIS structure without back surface $\mathrm{SnO}$ layer. The proposed solar cell performs better for ultra violet range whereas there is not any significant change in photo current for lower wavelength range of spectra.

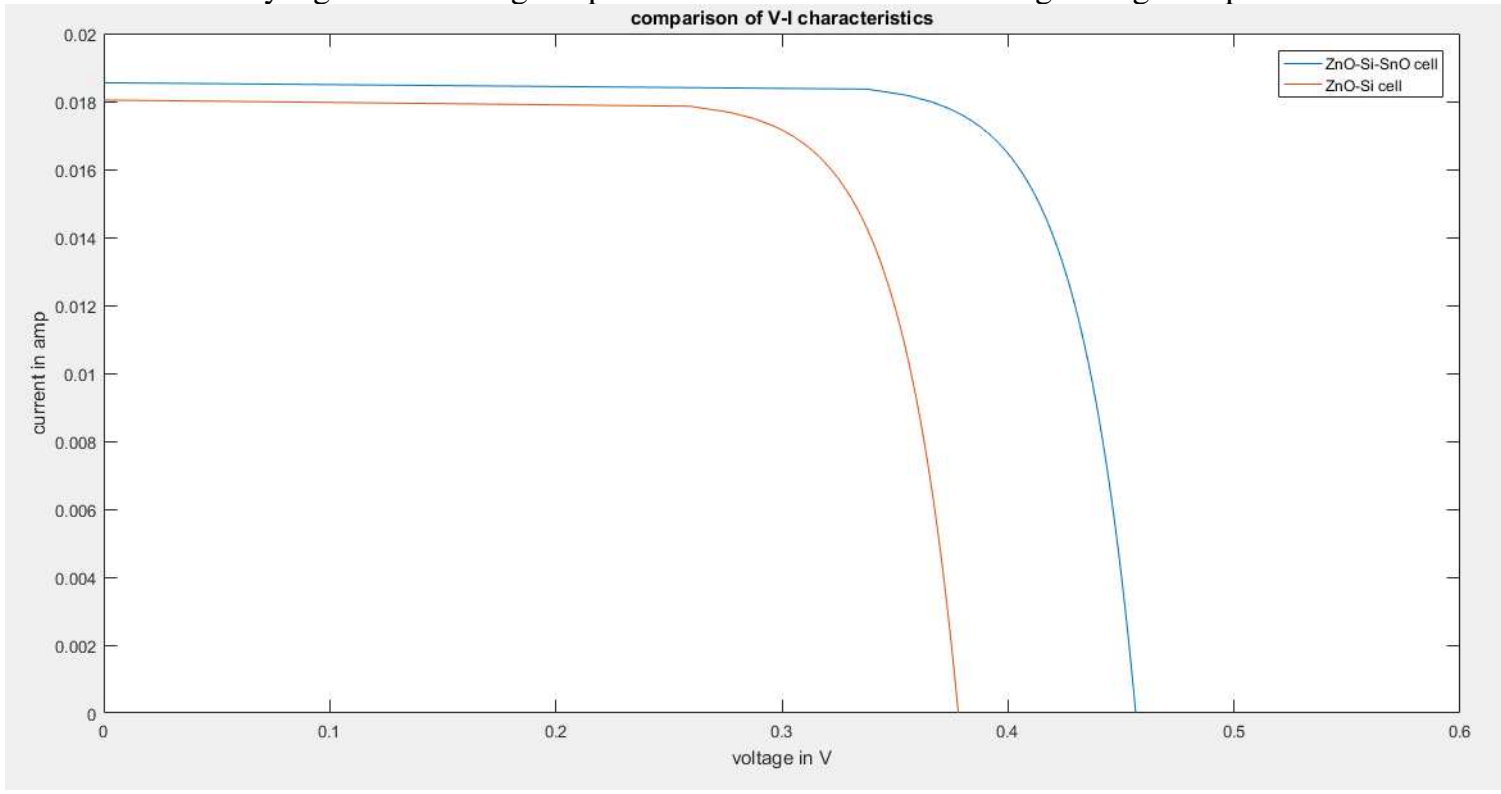

Fig. 6 V-I characteristics of dual and single SIS cell

The V-I characteristics was simulated for a $1 \mathrm{~cm}^{2}$ cell with and without back $\mathrm{SnO}$ film.

Table 2 Comparison between dual and single SIS solar cell

\begin{tabular}{|l|l|l|l|l|}
\hline & $\mathrm{J}_{\mathrm{SC}}$ in $\mathrm{mA} / \mathrm{cm}^{2}$ & $\mathrm{~V}_{\text {OC }}$ in volt & Form Factor $(\mathrm{FF})$ & \% Efficiency $(\eta)$ \\
\hline Dual SIS solar cell & 0.0186 & 0.4565 & 0.7903 & 6.6928 \\
\hline Single SIS solar cell & 0.0180 & 0.3780 & 0.7611 & 5.1908 \\
\hline
\end{tabular}

A comparative performance index table is shown in Table 2. We can see a significant improvement in both open circuit voltage and short circuit current. As a result the efficiency is expected to raise up to $\sim 6.7 \%$ from $\sim 5.2 \%$. The result for single SIS solar cell is quite close by the experimental result obtained by Untila et al [40]. The improvement of the $\mathrm{J}_{\mathrm{SC}}$ is the result of the change in collection probability for $\mathrm{p}-\mathrm{p}^{+}$depletion region at $\mathrm{p} \mathrm{Si-SnO}$ junction. Whereas the additional built in potential improved the open circuit voltage. 


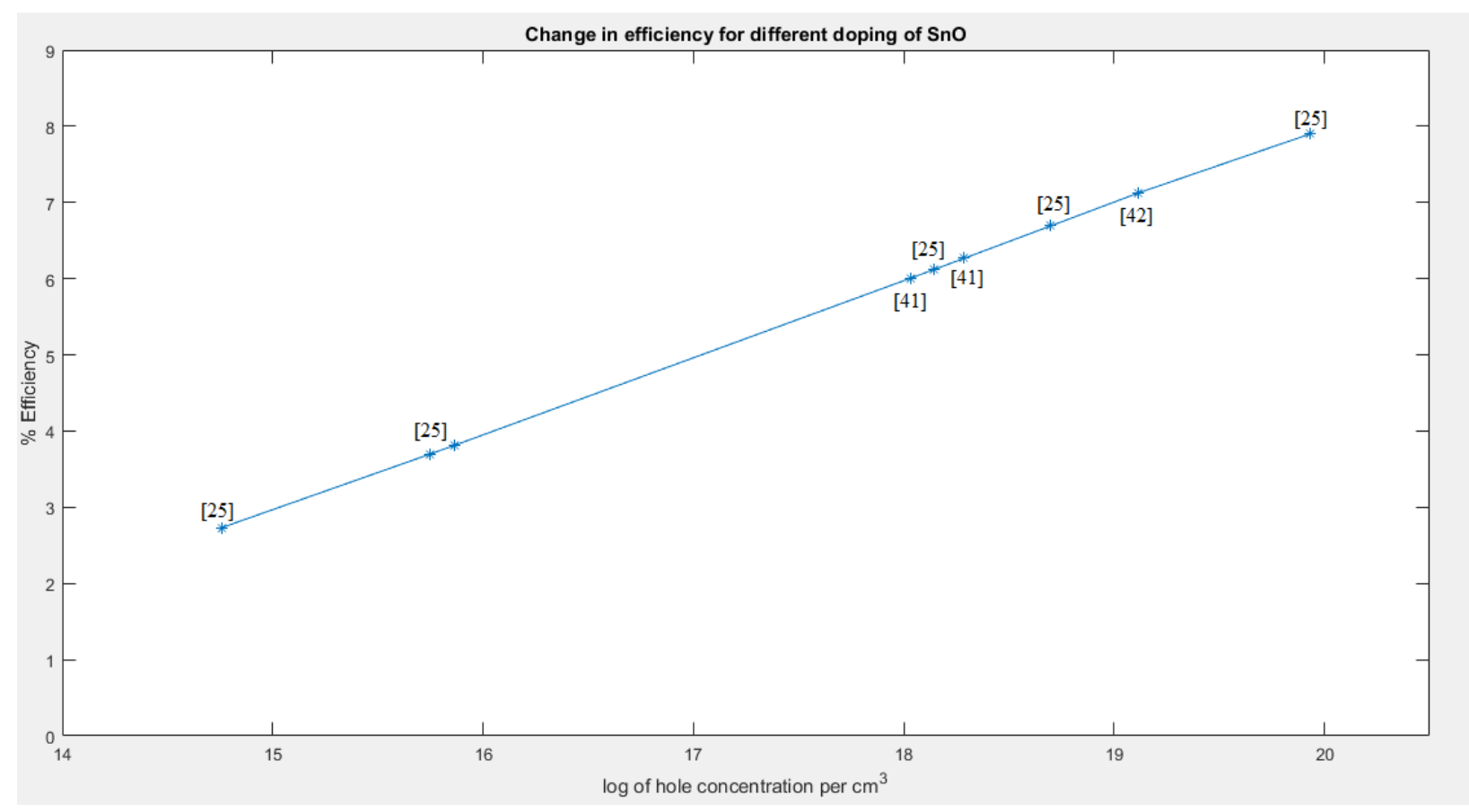

Fig. 7 Variation of efficiency of the cell with effective hole concentration of SnO layer

We have further varied the effective hole concentration of back surface SnO film. We have contemplated the effect of hole concentration of $\mathrm{SnO}$ layer in computed efficiency. Different values of hole concentration was taken into consideration as reported by other groups of scientists earlier. Different methods of deposition were considered with different physical conditions. Guo et al reported the effective concentration of hole carrier in $25^{\circ} \mathrm{C}$ and $300^{\circ} \mathrm{C}$ [25]. Hsu et al reported properties of deposited $\mathrm{SnO}$ by sputtering [41]. Bu reported sol gel deposition of p-type Sno:Mn:K film for solar cell application [42]. All the data of these reports were interposed in our mathematical model to get the efficiency of the proposed dual SIS solar cell. In Fig 7 we can observe efficiency increases exponentially as the carrier concentration increases. We observed that the efficiency was lesser for dual SIS structure than single Sis cell when the hole concentration of the back surface layer is less than that of the $\mathrm{p}-\mathrm{Si}$ substrate. When the hole concentration of $\mathrm{SnO}$ is less than that of $\mathrm{p}-\mathrm{Si}$ layer a reverse field is to be created which acts in opposition to the $\mathrm{ZnO}-\mathrm{Si}$ junction. This makes the overall efficiency lower than single ZnO-p Si SIS solar cell. The simulated result shown in Fig 7 leads us to an important expression of efficiency as a function of effective hole concentration of the back surface $\mathrm{p}^{+}$layer.

$\eta=m \ln \left(\frac{N_{a}}{N_{r e f}}\right) \ldots \ldots$

Where the constants $\mathrm{m}=0.4122473$ and $\mathrm{N}_{\text {ref }}=8.148582 \times 10^{11} \mathrm{~cm}^{-3}$ were computed from the graph. $\mathrm{N}_{\mathrm{a}}$ is the hole concentration of $\mathrm{SnO}$ in $\mathrm{cm}^{-3}$.

\section{Conclusion}

In this mathematical model we are proposing a very new hetero junction dual SIS solar cell which has $28.93 \%$ to $52.23 \%$ improvement in efficiency over the single SIS solar cell. We have approximated the efficiency as a function of carrier concentration of back surface layer carrier concentration. This shows a exponential increment of efficiency with carrier concentration. Though the overall efficiency is much lesser than the crystalline Si solar cell but the 
process involved in depositing the layers ob front and back surface was considered to be done with some simple chemical process mostly conducted in room temperature. This can avoid expensive annealing and diffusion process. This proposed cell thus has much opportunity to perform well in low energy and low budget applications. In this paper we are proposing a very new hetero junction structure with significant mathematical justification and low cost electro chemical experimentation. Since the SnO layer is shown to be beneficial for the solar cell application this paper indicates a green signal for the further development of dual SIS solar cell.

\section{Declaration}

Funding: No institutional funding was used

Conflicts of interest/Competing interests: Not any

Availability of data and material: Available with authors.

Code availability: Available with authors.

Authors' contributions:

Kaustuv Dasgupta: Writing the manuscript, Theoretical analysis, Coding, Result Analysis

Utpal Gangopadhyay: Ideation, Supervising, Data analysis

Anup Mondal: Supervising, data correction

Soma Ray: Technical support, Data analysis

Compliance with ethical standards: The study was not funded by any funding organization. MATLAB software used in the study is licensed under Meghnad Saha Institute of Technology. The authors declare that they have no conflicts of interest. This article does not contain any studies involving animals performed by any of the authors. This article does not contain any studies involving human participants performed by any of the authors.

Consent to participate: This article does not contain any studies involving human participants performed by any of the authors.

Consent for Publication: We give our consent for the publication of identifiable details, which can include photograph(s) and/or videos and/or case history and/or details within the text ("Material") to be published in the Silicon, Springer. Therefore, anyone can read material published in the Journal.

Acknowledgments: We acknowledge Meghnad Saha Institute of Technology for providing us with MATLAB software for simulation.

\section{References}

[1] C.E.Fritts, On a New form of Selenium Cell, and Some Electrical Discoveries made by its use; Am J Sci,Vol. 26,465-472(1883)

[2] S. J. Fonash, Outline and comparison of the possible effects present in a metal-thin-film-insulatorsemiconductor; Journal of Applied Physics 47, 3597 (1976)

[3] J. Shewchun, R. Singh, and M. A. Green, Theory of metalinsulatorsemiconductor solar cells, J. Appl. Phys. 48, 765 (1977)

[4] A. K. Ghosh, C. Fishman, and T. Feng, SnO2/Si solar cells-heterostructure orSchottkybarrier or MIS type device,J. Appl. Phys. 49, 3490 (1978)

[5] P. Van Helen, R.P.Mertens, R.J.Van Overstraeten and R.E.Thomas, New Ti0,-MIS and Si02-MIS Silicon Solar Cells, IEEE TRANSACTIONS ON ELECTRON DEVICES, VOL. ED-25, NO. 5,(1978).

[6] H.B.Saim qnd D.S.Campbell, Properties of Indium-Tin-Oxide(ITO)/Silicon Heterojunction Solar Cells by Thick -Film Techniques, Solar Energy Materials 15, 249-260(1987)

[7] S.Maifi, K.Lagha, F.Boumedine and M.S.Belkaid, M-I-S-S Structure Based Silicon and TCO; IEEE Transactions(2009) 
[8] G.G. Untila, T.N. Kost, A.B. Chebotareva, ITO/SiOx/n-Si heterojunction solar cell with bifacial $16.6 \% / 14.6 \%$ front/rear efficiency produced by ultrasonic spray pyrolysis: Effect of conditions of SiOx growth by wet-chemical oxidation, Solar Energy, Volume 204, 2020, Pages 395-405

[9] Quanxi Jia, Chapter 13 - Conductive metal oxide thin films,Editor(s): Hari Singh Nalwa, Handbook of Thin Films, Academic Press, 2002, Pages 677-698,

[10] Zhao, J., Wang, A. and Green, M.A. (1999), 24.5\% Efficiency silicon PERT cells on MCZ substrates and 24.7\% efficiency PERL cells on FZ substrates. Prog. Photovolt: Res. Appl., 7: 471-474.

[11] Lamia Znaidi, Sol-gel-deposited ZnO thin films: A review, Materials Science and Engineering: B, Volume 174, Issues 1-3, 2010, Pages 18-30

[12] E. A. Irene and Y. J. van der Meulen, Silicon Oxidation Studies: Analysis of SiO2 Film Growth Data, 1976 J. Electrochem. Soc. 1231380

[13] K. Vanbesien, P. De Visschere, P.F. Smet, D. Poelman, Electrical properties of Al2O3 films for TFEL-devices made with sol-gel technology, Thin Solid Films, Volume 514, Issues 1-2, 2006, Pages 323-328

[14] Marikkannan, M.; Vishnukanthan, V.; Vijayshankar, A.; Mayandi, J. \& Pearce, J. M., A novel synthesis of tin oxide thin films by the sol-gel process for optoelectronic applications, AIP Advances, 2015, 5, 027122

[15] Hussain, B.; Aslam, A.; Khan, T.M.; Creighton, M.; Zohuri, B. Electron Affinity and Bandgap Optimization of Zinc Oxide for Improved Performance of $\mathrm{ZnO} / \mathrm{Si}$ Heterojunction Solar Cell Using PC1D Simulations. Electronics $2019,8,238$.

[16] Pearson, G. L. \& Bardeen, J. Electrical Properties of Pure Silicon and Silicon Alloys Containing Boron and Phosphorus , Phys. Rev., American Physical Society, 1949, 75, 865-883

[17] Kachirayil J. Saji, Y.P. Venkata Subbaiah, Kun Tian, Ashutosh Tiwari, P-type SnO thin films and SnO/ZnO heterostructures for all-oxide electronic and optoelectronic device applications, Thin Solid Films, Volume 605, 2016, Pages 193-201

[18] Saji, K. J., Tian, K., Snure, M., Tiwari, A. (2016). 2D Tin Monoxide-An Unexplored p-Type van der Waals Semiconductor: Material Characteristics and Field Effect Transistors. Adv. Electron. Mater., 2: 1500453.

[19] D.P. Norton, Y.W. Heo, M.P. Ivill, K. Ip, S.J. Pearton, M.F. Chisholm, T. Steiner, ZnO: growth, doping \& processing, Materials Today, Volume 7, Issue 6, 2004

[20] Peng, H.; Bikowski, A.; Zakutayev, A. \& Lany, S., Pathway to oxide photovoltaics via band-structure engineering of SnO, APL Materials, 2016, 4, 106103

[21] Mandal, L.; Askari, S. S. A.; Kumar, M. \& Das, M. K., Band offset engineering for p-SnO/n-mc-Si heterojunction solar cell , Applied Physics Letters, 2020, 116, 234106

[22] M. E. Law, E. Solley, M. Liang and D. E. Burk, "Self-consistent model of minority-carrier lifetime, diffusion length, and mobility," in IEEE Electron Device Letters, vol. 12, no. 8, pp. 401-403, Aug. 1991.

[23] X. J. Zhang, W. Ji, and S. H. Tang, "Determination of optical nonlinearities and carrier lifetime in ZnO," J. Opt. Soc. Am. B 14, 1951-1955 (1997)

[24] R. Ghosh, G.K. Paul, D. Basak, Effect of thermal annealing treatment on structural, electrical and optical properties of transparent sol-gel ZnO thin films, Materials Research Bulletin, Volume 40, Issue 11, 2005, Pages 
1905-1914

[25] Guo, W.; Fu, L.; Zhang, Y.; Zhang, K.; Liang, L. Y.; Liu, Z. M.; Cao, H. T. \& Pan, X. Q., Microstructure, optical, and electrical properties of p-type SnO thin films , Applied Physics Letters, 2010, 96, 042113

Materials Research Express, IOP Publishing, 2020, 6, 125915

[26] Richard S. Muller, Theodore I. Kamins, Device Electronics for Integrated Circuits, 3rd Edition, October 2002

[27] Matsuura, H., Calculation of band bending in ferroelectric semiconductor, New Journal of Physics, IOP Publishing, 2000, 2, 8-8

[28] Markvart, Tom \& Castañer, Luis. (2003). Chapter IA-2. Semiconductor Materials and Modelling.

[29] Donolato, C., A reciprocity theorem for charge collection, Applied Physics Letters, 1985, 46, 270-272

[30] Donolato, C., Reciprocity theorem for charge collection by a surface with finite collection velocity: Application to grain boundaries , Journal of Applied Physics, 1994, 76, 959-966

[31] Hermle, M.; Granek, F.; Schultz, O. \& Glunz, S. W., Analyzing the effects of front-surface fields on backjunction silicon solar cells using the charge-collection probability and the reciprocity theorem, Journal of Applied Physics, 2008, 103, 054507

[32] Slimane Chala, Nouredine Sengouga, Fahrettin Yakuphanoğlu, Saâd Rahmane, Madani Bdirina, İbrahim Karteri, Extraction of $\mathrm{ZnO}$ thin film parameters for modeling a ZnO/Si solar cell, Energy, Volume 164, 2018, Pages $871-880$

[33] Moreno-Hernandez, I. A.; Yalamanchili, S.; Fu, H. J.; Atwater, H. A.; Brunschwig, B. S. \& Lewis, N. S., Conformal SnOx heterojunction coatings for stabilized photoelectrochemical water oxidation using arrays of silicon microcones , J. Mater. Chem. A, The Royal Society of Chemistry, 2020, 8, 9292-9301

[34] Park, K. C., Ma, D. Y., \& Kim, K. H. (1997). The physical properties of Al-doped zinc oxide films prepared by RF magnetron sputtering. Thin Solid Films, 305(1-2), 201-209.

[35] Green, M.A. and Keevers, M.J. (1995), Optical properties of intrinsic silicon at 300 K. Prog. Photovolt: Res. Appl., 3: 189-192.

[36] Liu, Q.-J., Liu, Z.-T., \& Feng, L.-P. (2010). First-principles calculations of structural, electronic and optical properties of tetragonal $\mathrm{SnO} 2$ and $\mathrm{SnO}$. Computational Materials Science, 47(4), 1016-1022.

[37] Kaustuv Dasgupta, Soma Ray, Anup Mondal, Utpal Gangopadhyay, Review on different front surface modification of both n+-p-p+ and p+-n-n+ C- Si solar cell, Materials Today: Proceedings, Volume 4, Issue 14, 2017 , Pages 12698-12707

[38] Schroder D. K. and Meier D. L, "Solar cell contact resistance-A review," in IEEE Transactions on Electron Devices, vol. 31, no. 5, pp. 637-647, May 1984.

[39] McIntosh, Keith \& Honsberg, C.. (2000). The Influence of Edge Recombination on a Solar Cell's Iv Curve.

[40] G.G. Untila, T.N. Kost, A.B. Chebotareva, Bifacial 8.3\%/5.4\% front/rear efficiency ZnO:Al/n-Si heterojunction solar cell produced by spray pyrolysis, Solar Energy, Volume 127, 2016, Pages 184-197

[41] Hsu, P.-C.; Chen, W.-C.; Tsai, Y.-T.; Kung, Y.-C.; Chang, C.-H.; Hsu, C.-J.; Wu, C.-C. \& Hsieh, H.-H. Fabrication of p-Type SnO Thin-Film Transistors by Sputtering with Practical Metal Electrodes Japanese Journal of Applied Physics, IOP Publishing, 2013, 52, 05DC07 
[42] Ian Yi-yu Bu, Novel sol-gel deposited p-type SnO:Mn:K for solar cell applications, Optik, Volume 162, 2018, Pages 121-125 
Figures

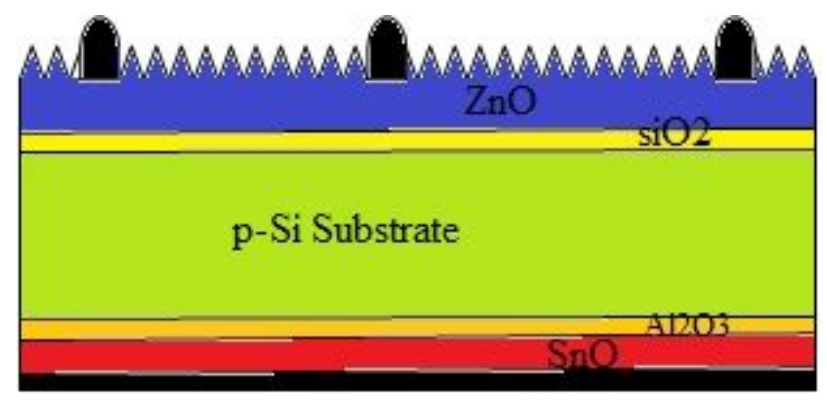

Figure 1

Dual SIS structure

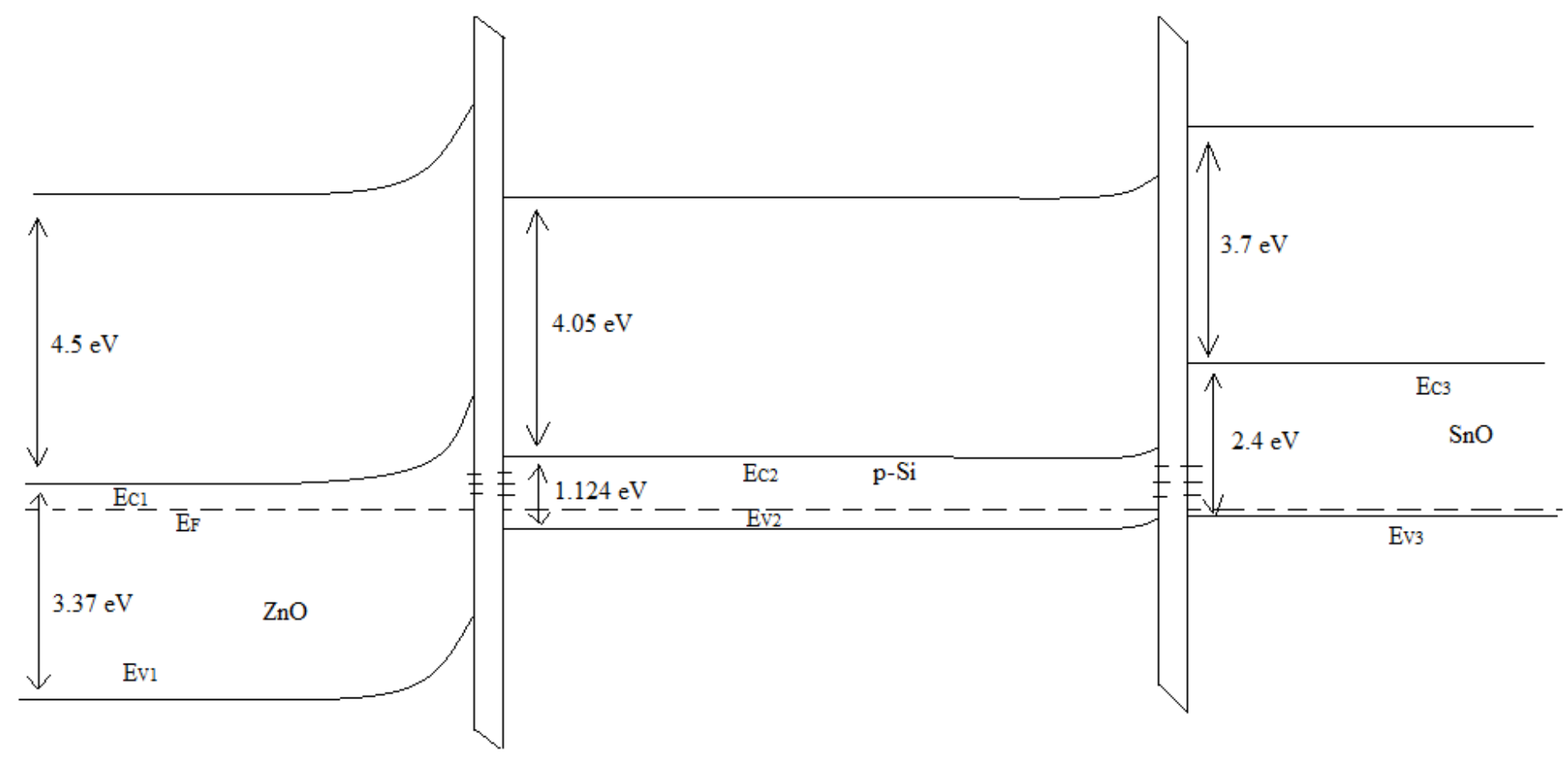

Figure 2

Energy band diagram of dual SIS structure 


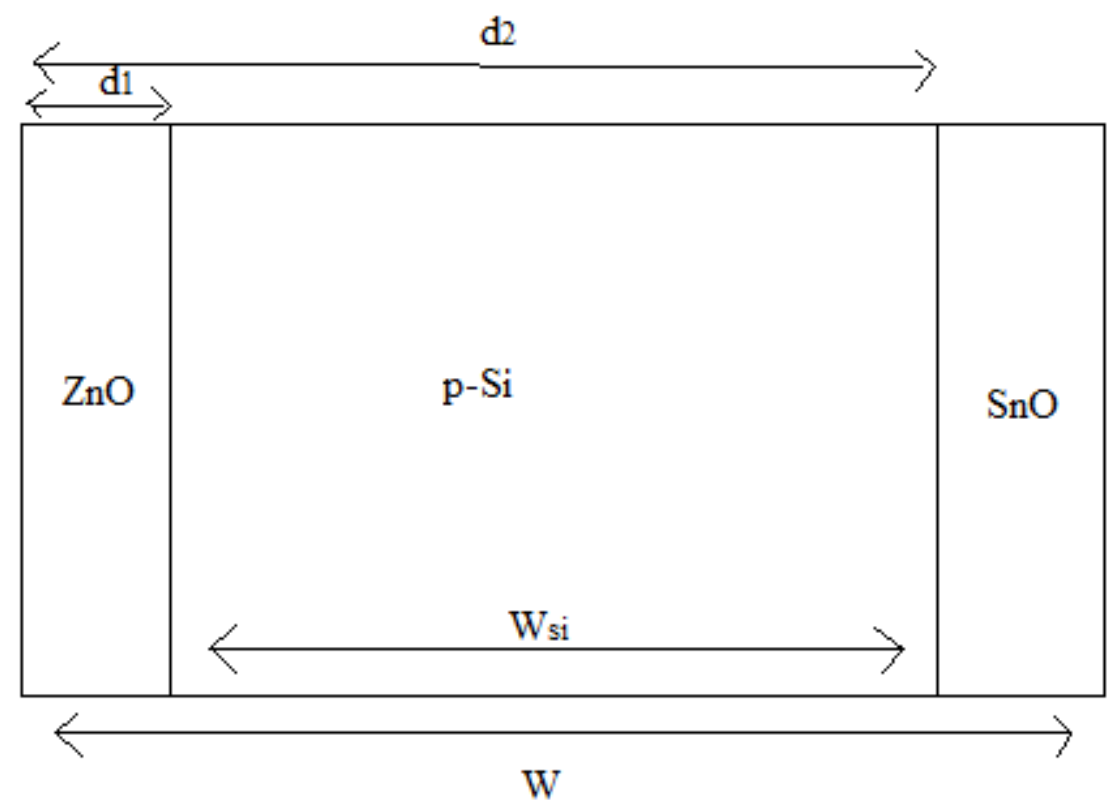

Figure 3

Different semiconductor region in dual SIS structure

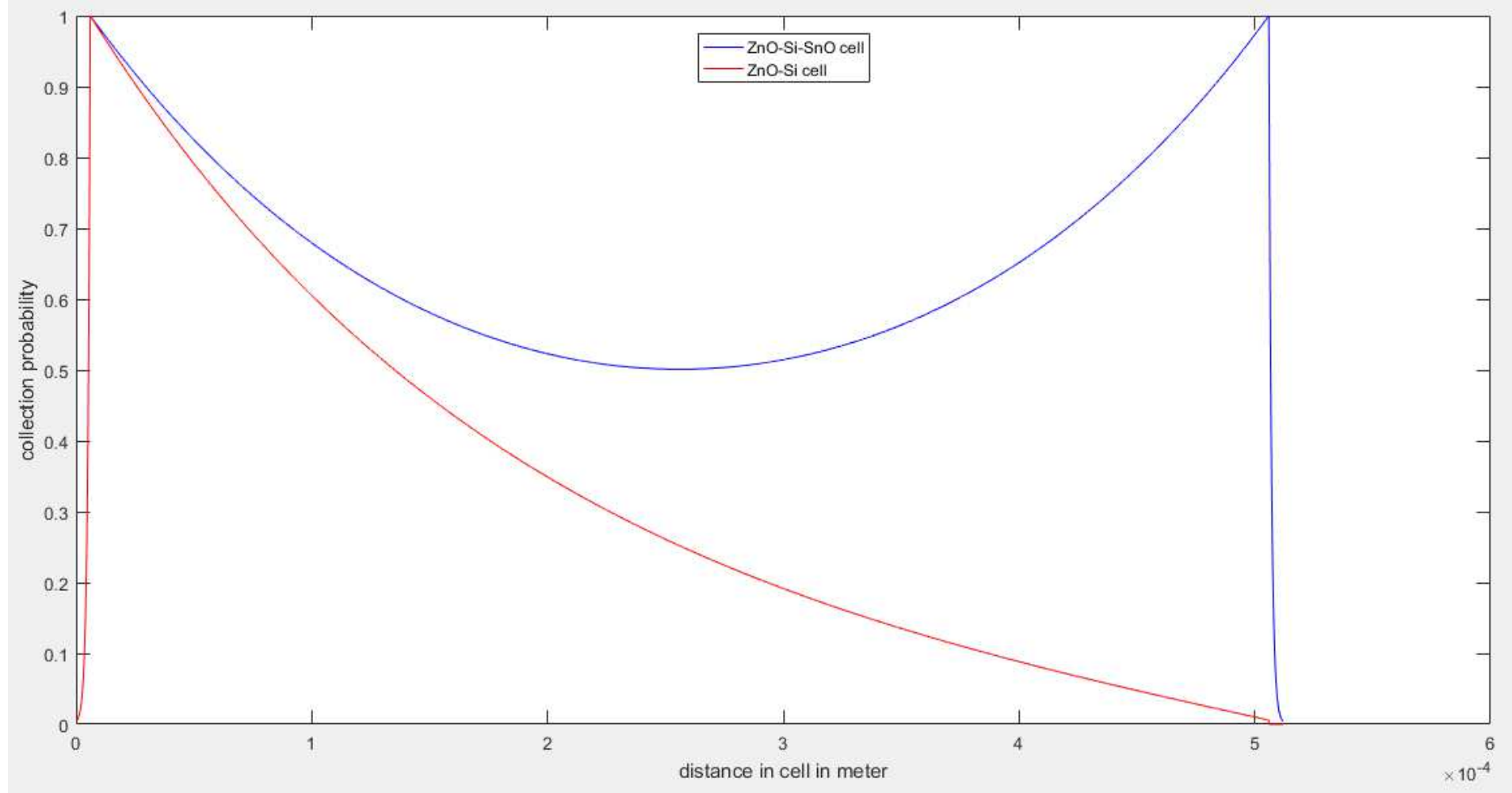

Figure 4

Collection probability 


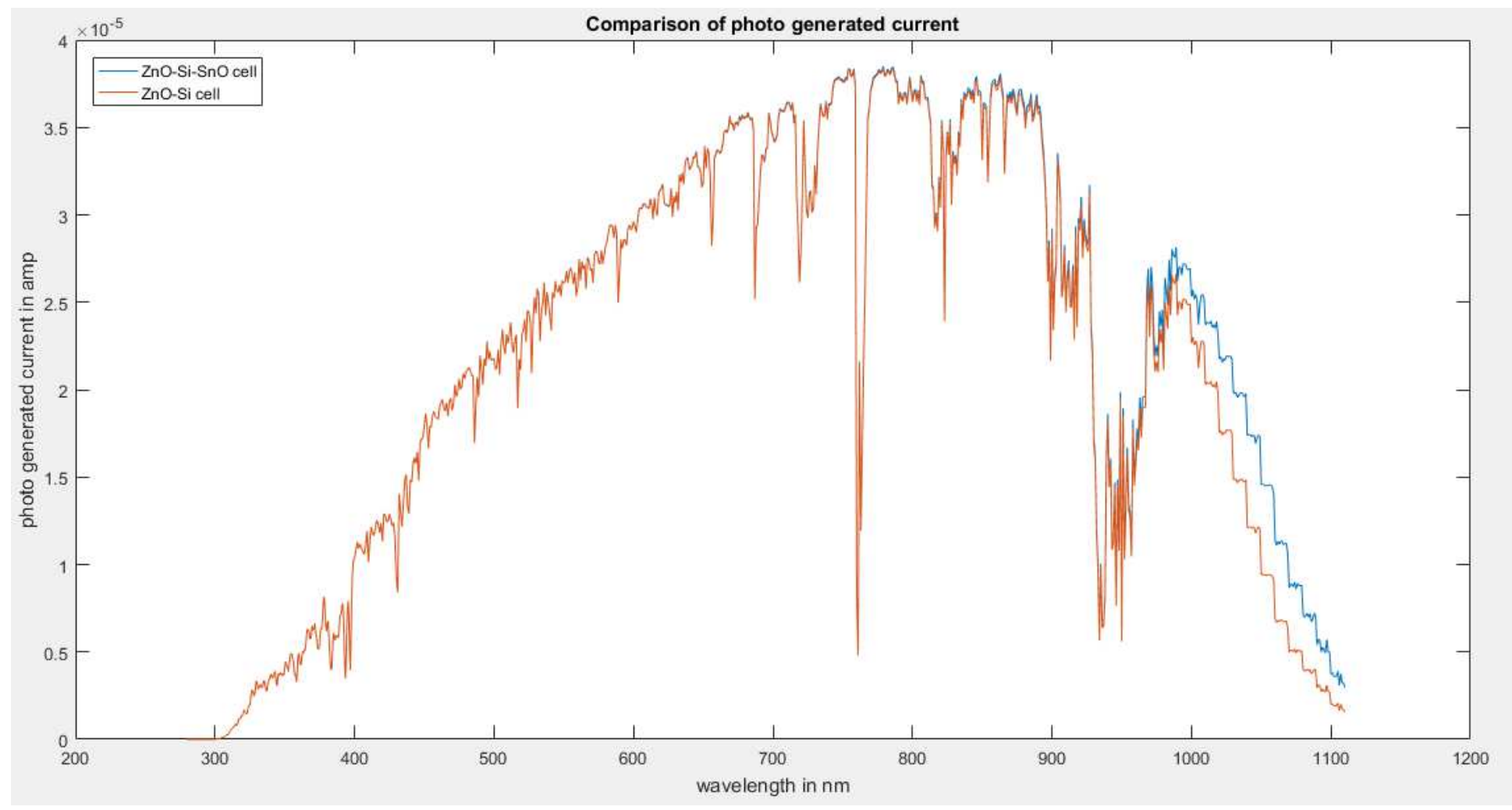

Figure 5

Photo generated current for different wavelength

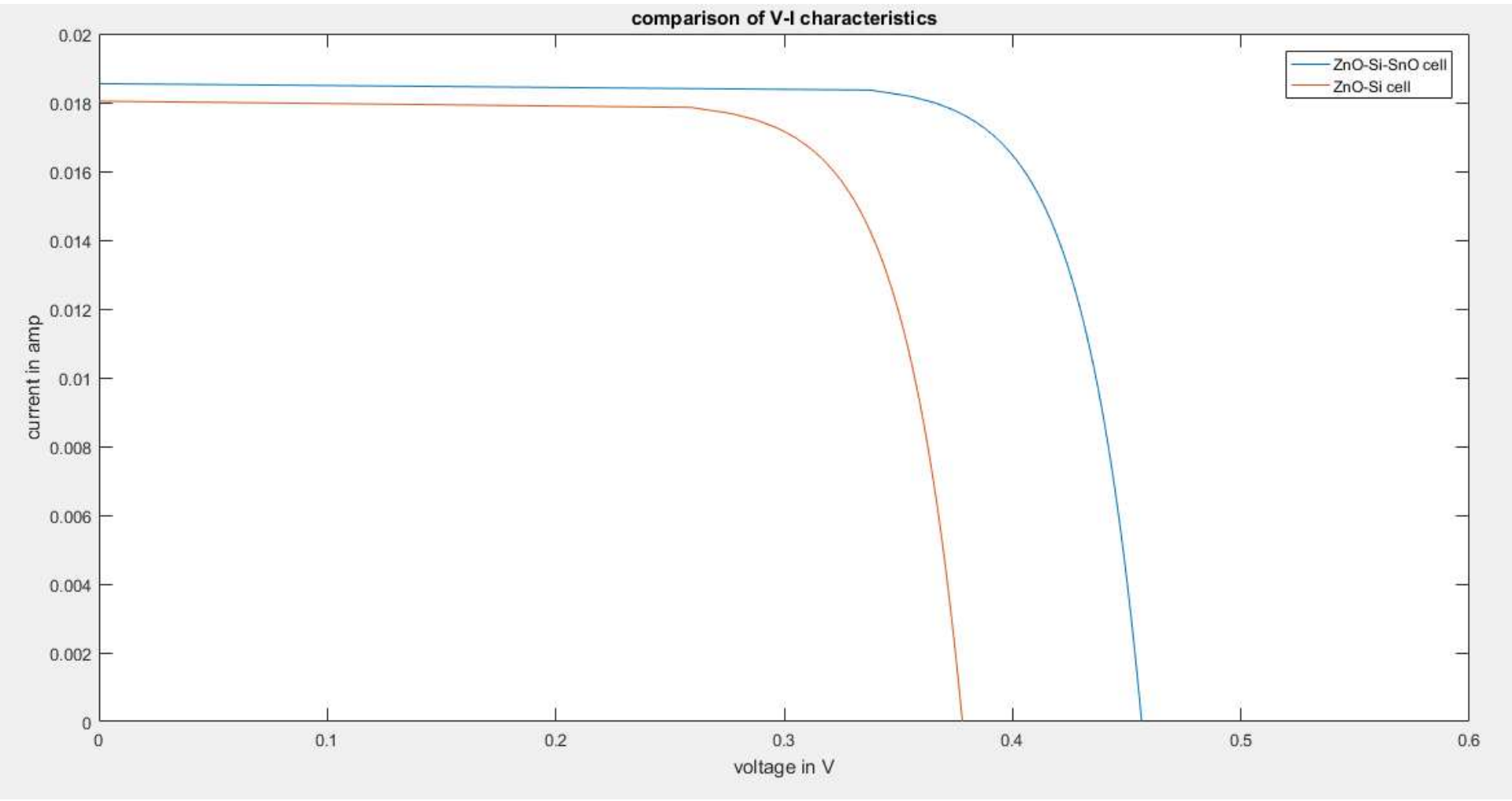

Figure 6

V-I characteristics of dual and single SIS cell 


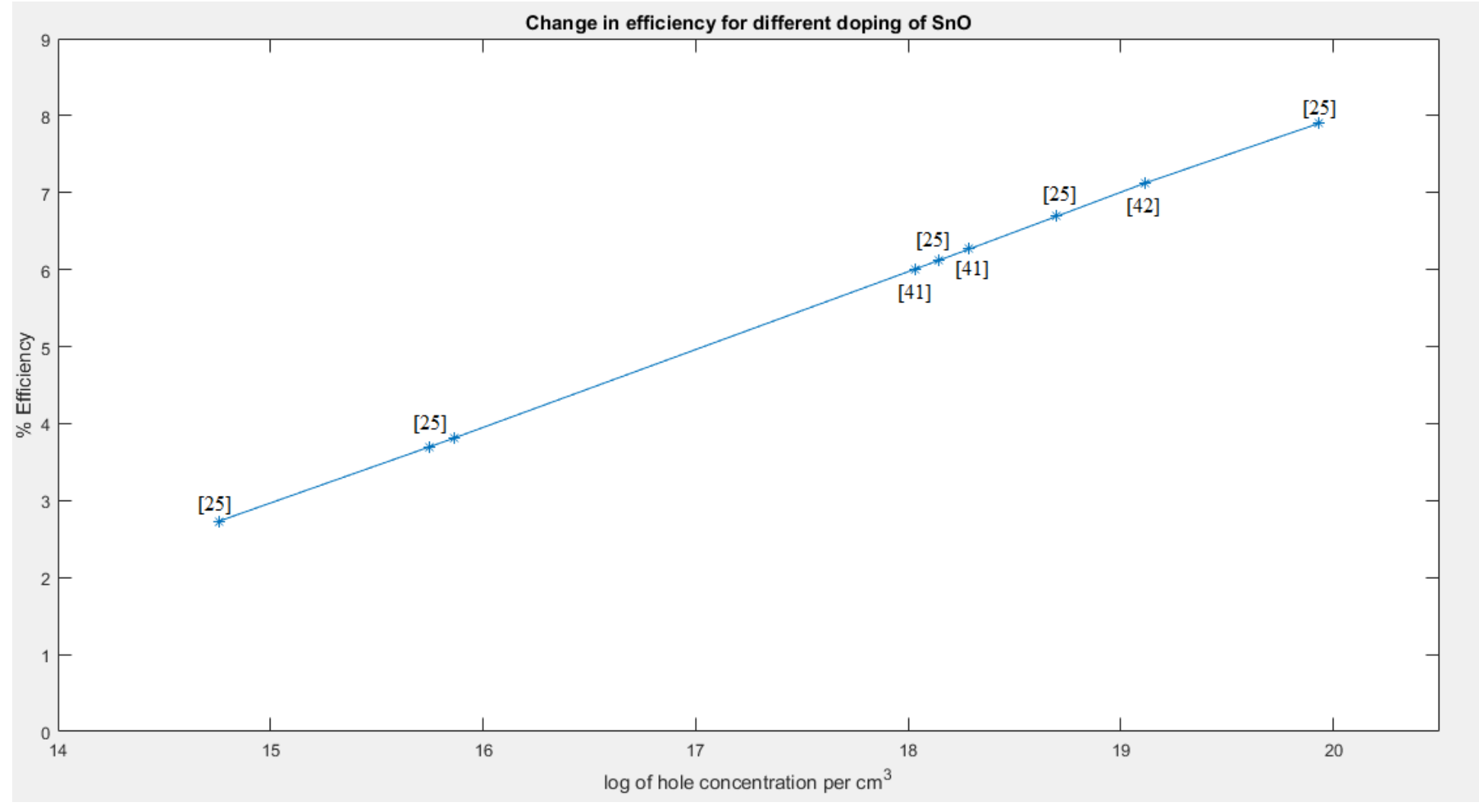

Figure 7

Variation of efficiency of the cell with effective hole concentration of SnO layer 